\title{
Port selection based on customer questionnaire: a case study of German port selection
}

\author{
Yisong Lin ${ }^{*}$ (D) and Xuefeng Wang
}

\begin{abstract}
A new research idea regarding port selection concerns customer-oriented, rather than product-oriented, thinking. Through investigation and interviews with over 280 active customers in the global shipping industry, port selection criteria were proposed, and an evaluation scheme based on the responses to a questionnaire survey is compared with a scheme based on the weight calculation of the analytic hierarchy process. The results indicate that due to different priorities between customers and container carriers, port selection is sometimes inconsistent. Against the background of deployment of large-scale vessels, over-capacity has become normal in the industry; this study has great practical value for the whole industry.
\end{abstract}

Keywords: Customer questionnaire, Port selection, Customer orientation, Product orientation, Analytic hierarchy process

\section{Introduction}

An obvious change in the container shipping industry is the upsizing of container vessels due to large-scale vessel deployment. According to industry consultant Alphaliner, the average size of global container fleet increased from 2606 TEU (twenty-foot equivalent unit) in 2000 to 4074 TEU by the end of 2018 , with container vessels over 10,000 TEU accounting for $32 \%$ of the fleet, respectively. The proportion of large-scale vessels will further increase following new orders and deployment of even larger vessels of over 20,000 TEU. The potential available calling ports are relatively limited in number, due to limitations of channel and berth draft, berth length, terminal facilities, and market capacity. Taking vessels over 13,300 TEU as an example, only 53 ports worldwide can accommodate this type of vessel, with 17 ports located in Northeast Asia, 27 in Europe and the Mediterranean region, 7 in the Middle East, and 2 in North America (Fig. 1).

The upsizing of container vessels has significantly changed the port selection of container carriers. The limitation of potential available calling ports leads to

\footnotetext{
*Correspondence: lin.yisong@coscoshipping.com; 17068495@qq.com Logistics Engineering and Research Center, Shanghai Maritime University, Pudong, China
}

homogeneity in the products and services of container carriers. As low-cost ports gain traction, whether to transfer service routes to emerging, low-cost ports remains a hot topic. In terms of German port selection, Hamburg remains the most popular calling port among the four German ports of Hamburg, Wilhelmshaven, Bremen, and Bremerhaven. However, the natural condition of Hamburg port is not ideal, as the seaport's entrance draft is only $14.5 \mathrm{~m}$ and its export draft is only $13.3 \mathrm{~m}$. Large ships (over 18,000 TEU) generally require drafts of more than $16 \mathrm{~m}$; full-load vessels are required to wait for the tide to pass through. Wilhelmshaven appears to be a good alternative, as the water depth reaches $18 \mathrm{~m}$ and it is located close to the open sea and an international waterway. A question then arises regarding customers' actual choices, as well as the determinants thereof.

In this research, a questionnaire was distributed to 315 various active shipping customers, yielding 287 useable responses, Respondents included cargo owners, and freight-forwarding companies. The indicators and reasons behind their selection of a German port were examined in detail. The evaluation scheme based on the indicators and corresponding weight from the questionnaire survey was compared with an Analytic Hierarchy 


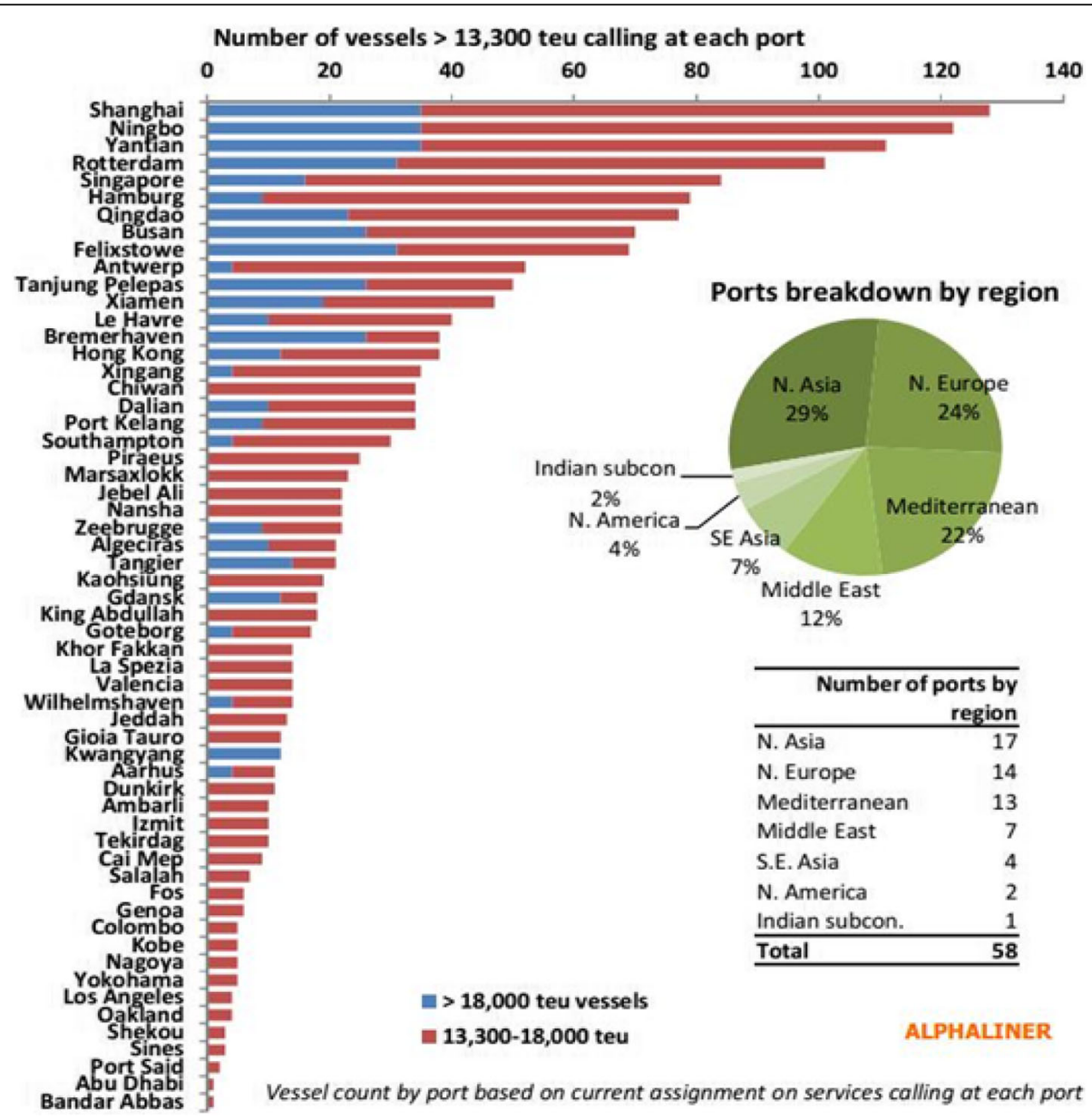

Fig. 1 Receiving ports above 13300TEU as at Dec 2015. (Source: Alphaliner)

Process (AHP) solution to provide a solution regarding port selection based on customer-oriented thinking.

\subsection{Literature review}

Product-oriented thinking is very common in the industry; therefore, the existing literature on port selection mainly focuses on the position of container liners and seeks to optimize costs and other criteria such as port efficiency, location, service, and physical infrastructure. Taih-Cherng et al. (2003) evaluated the importance of various criteria in transshipment port selection from a container carrier's perspective and revealed that port competitiveness mainly depends on carriers' costs and efficiency in loading and discharging [1]. Guy and Urli (2006) examined how the combined importance of quality of infrastructure, cost, service, and geographical location affect shipping lines' port choice [2]. Chang et al. (2008) examined the different factors affecting shipping lines' port selections. They collected data through a survey of shipping companies and analyzed it from the varying perspectives of trunk liners and feeder service providers [3]. Nguyen (2011) constructed a model for port selection by minimizing total cost and two sensitivity analyses were used to evaluate different service patterns, and the efficiency of large vessels in the scope context of a logistics network [4]. Kadaifci et al. (2019) used a multi-criteria decision-making approach to examine the effects of transportation cost, geographical location, infrastructure, and technical conditions on port selection [5]. Nazemzadeh and Vanelslander (2015) analyzed port selection criteria through questionnaire surveys of three different industry groups [6]. It can be concluded that a common characteristic of these studies is the concern for cost saving. Decision-making was based on cost optimization and container carrier's concerns regarding improving efficiency, service and geographical location convenience, and so on.

Other studies examine indicators such as hinterland connection, feeder connectivity, scale economies, cargo balance, and environmental issues. Bart et al. (2008) investigated how hinterland connections, port tariffs, feeder connectivity, and environmental issues affect deep-sea container operators' port selections [7]. Tand et al. (2011) investigated the quality characteristics of port selection. 
Findings revealed that port efficiency and scale economies are the important dimensions influencing container carriers' selection [8]. Based on a case study of the Spanish container trade, Veldman et al. (2013) introduced new variables such as coastline and inland transport cargo balance to expand upon earlier research [9]. Some studies established the criteria and sub-criteria system for container carrier's port selection. Onut et al. (2011) examined the criteria and sub-criteria for port selection through a case study of port selection in the Marmara region of Turkey [10] .Chou (2010) examined the criteria and subcriteria from shipping lines' perspectives [11]. Button et al. (2015) investigated how incorporating subjective elements affects port selection [12]. In addition, a few papers have examined port selection from the viewpoint of container liners in specific environments. Yeo et al. (2014) analyzed port selection in uncertain environments [13]. Notteboom et al. (2017) investigated the complex link between port selection by shipping alliance members and changing organizational routines [14].

Based on the above mentioned literature review, it can be concluded that the related indicators were well reflected in port selection from the viewpoint of container liners. However, it remains a question as to whether customers match the container carriers' choices and if their concerns are different. It is necessary to examine port selection from the viewpoint of customers especially under the current trend of container vessels' upsizing.

There are very few papers that examine the effects of customers' port selection choices. Tongzon (2009) examined the major aspects influencing port choice from the perspective of Southeast Asian freight forwarders [15]. Kashiha et al. (2016) investigated how geography and transportation costs influence shippers' decisions regarding port selection [16]. Balci et al. (2018) studied terminal competition and selection criteria in the dry bulk market via a case study of Izmir, Turkey [17]. A common research approach for above mentioned literature was to rate the pre-selected indicators by sampling customers; indicator weight was calculated in a different manner. However, as all indicators were included in the pre-selection, the effects of subdividing indicators on customers' port selections were not studied. Furthermore, the indicators' weights (calculated by the mathematical model) were not verified, which is precisely what this paper intends to contribute to the literature.

\section{3. Results and discussion}

\subsection{3 .1 Survey participants}

A total of 315 questionnaires were issued, and 287 valid questionnaires were recovered. Among the 287 valid responses, 219 (76\%) participants (shipping industry customers) had a global volume of less than 99,999 TEU/ year; 32 (11\%) had a global volume of 100,000 to 499 ,
999 TEU/year; 16 (6\%) had a global volume of 500,000 to $999,999 \mathrm{TEU} /$ year; $11(4 \%)$ had a global volume of 1 , 000,000 TEU/year, while volume size is not specified for $9(3 \%)$ participants.

In terms of participants' volume on the Asia-Europe route, 204 (71\%) have a volume of 9999 TEU or less; 45 (16\%) have a volume of $10,000 \mathrm{TEU}$ to $49,999 \mathrm{TEU} /$ year; $17(6 \%)$ have a volume of 50,000 to 99,999 TEU/year; 13 (5\%) have a volume of 100,000 TEU/year and above; the annual volume size was not specified by $8 \quad(2 \%)$ participants.

In terms of the cargo volume distribution in Germany, there are $217(76 \%)$ participants with German shipments of $4999 \mathrm{TEU} /$ year or less; 24 (8\%) with shipments between 5000 and 9999 TEU/year; 26 (9\%) with shipments between 10,000 and 49,999 TEU/year; seven (2\%) with shipments of 50,000 TEU/year and above; the volume of German shipments on the Asia-Europe route was not specified by 13 (5\%) participants.

While the questionnaire covers customers of various sizes in the market, it mainly includes small- and medium-sized entities. This is consistent with the proportional distribution of various customers. Customers selected for the survey questionnaire have a wide range of representation in port selection (Fig. 2).

\subsection{2 Survey indicators setting}

Traditionally, under the guidance of "product-oriented" thinking, container carriers believe that as long as the calling ports can contribute to reducing the network cost, improve delivery time, and maintain uniqueness, selection of such ports makes good business sense. However, through the questionnaire survey, a totally different concern was found regarding port selection. The level indicators proposed by participants in the questionnaire survey include freight competitiveness, service capability, cooperation and relationship, and "others" (which includes aspects such as

Global Volume Distribution of Investigated Customers

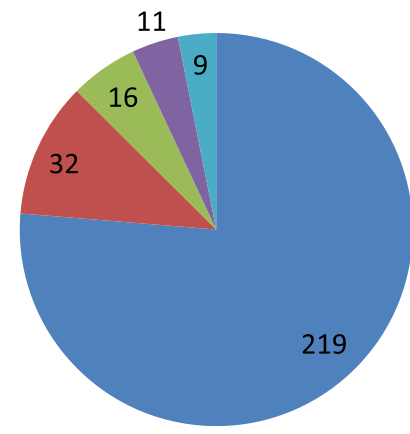

• Below 99,999TEU/year

- Between 100,000TEU499,999TEU/year

- Between 500,000TEU999,999TEU/year

1,000,000TEU/year and above

$\square$ Not Specified

Fig. 2 Global volume distribution of investigated customers. (Source: Authors) 
container liners' strategic compatibility, reputation, and financial situation). A number of subdivided indicators comprise the elements for evaluation of the level indicators. Correspondingly, these levels were also named as secondary indicators. Both types of indicators are key elements in customers' port selection. Therefore, this is the evaluation indicator for assessing customer-oriented thinking. The composition and weights of the level indicators and secondary indicators are shown in Table 1.

In the questionnaire survey regarding port selection indicators, multiple choices were designed so as to examine customers' concern on different indicators. Therefore, the sum of all options was used to calculate the weights of indicators. Among the participants, 259 (41.5\%) selected "Freight Competitiveness" 223 (35.7\%) selected "Service Capability" 122 (19.6\%) selected "Cooperation and Relationship" while 20(3.2\%) selected "Others" respectively.

In addition, 120 (42\%) participants indicated that they would generally not change the core carrier; 75 would change their core carrier at any time, accounting for 26\%; 52 would change their core carrier every year, accounting for $18 \%$; 40 (14\%) do not have fixed core carriers; The 120 participants who selected "basically unchanged" cover all global NVOCCs (non-vessel operating common carriers) with cargo volumes above 50,000 TEU/year in Germany, which indicates that global NVOCCs appear to be more stable than small- and medium-sized freight-forwarding companies.

\subsection{3 Survey results and discussion}

The main ports available in Germany are the ports of Hamburg, Bremen, Bremerhaven, and Wilhelmshaven. According to the results of our survey, the port of Hamburg is still the preferred calling port for most customers. A total of 276 (79\%) participants selected Hamburg; 37 (11\%) selected Bremen; 30 (9\%) selected Bremerhaven; only four (1\%) selected Wilhelmshaven as their preferred calling port.

The reasons for selection were analyzed through the questionnaire survey. A total of 197 (38\%) participants attributed the aforementioned choices to "Sailing Frequency," while 123 (24\%) participants attributed the reason to "Distribution Cost" Interviews revealed that many distribution centers are located near the port of Hamburg and its surrounding areas and switching to Wilhelmshaven and Bremerhaven will significantly increase the cost of logistics and distribution. A total of 115 participants (22\%) attributed their selection to the "Collection and Distribution System". (Fig. 3).

Further research on potential change of ports showed that 30 participants (11\%) are willing to change to the port of Wilhelmshaven, but 98 (34\%) participants clearly stated that they will not accept Wilhelmshaven; 159 (55\%) participants indicated that a switch was "uncertain" or that it would happen "depending on the service".

The survey revealed that when evaluating a potential change, customers pay the highest attention to "Better Freight Rate." A total of 234 (43\%) participants selected "Better Freight Rate," 110 (20\%) selected "Efficient

Table 1 Main indicators of port selection by customers. (Source: Authors)

\begin{tabular}{|c|c|c|c|c|}
\hline Level Indicators & Number & Secondary Indicators & Indicators Description & Weight \\
\hline \multirow[t]{5}{*}{ Freight Competitiveness } & 1 & Freight Rate & Refers to the freight offer, relative to the competitiveness of competitors. & $40 \%$ \\
\hline & 2 & Side Condition & Refers to credit terms, demurrage and detention terms, drop off condition etc. & $30 \%$ \\
\hline & 3 & Volume Incentive & Refers to rebates when fulfilling volume target. & $20 \%$ \\
\hline & 4 & Freight Stability & Refers to the freight policy stability, consistency. & $5 \%$ \\
\hline & 5 & Quotation Efficiency & Refers to the efficiency of freight offer. & $5 \%$ \\
\hline \multirow[t]{5}{*}{ Service Capability } & 1 & Service Route Quality & $\begin{array}{l}\text { Refers to transit time, frequency, on-time performance and uniqueness of the } \\
\text { service route. }\end{array}$ & $50 \%$ \\
\hline & 2 & Cargo Tracing & Refers to the integrity, accuracy and timeliness of cargo tracing. & $20 \%$ \\
\hline & 3 & $\begin{array}{l}\text { Transshipment } \\
\text { Efficiency }\end{array}$ & Refers to efficiency of transshipment. & $20 \%$ \\
\hline & 4 & Emergency Response & Refers to capability and efficiency in any urgent case. & $5 \%$ \\
\hline & 5 & IT System & Refers to IT system connection and data exchanging. & $5 \%$ \\
\hline \multirow{3}{*}{$\begin{array}{l}\text { Cooperation and } \\
\text { Relationship }\end{array}$} & 1 & Global Cooperation & Refers to cooperation with container carriers in all trade lanes. & $40 \%$ \\
\hline & 2 & Cooperative History & Refers to the cooperative history and expectation in future. & $40 \%$ \\
\hline & 3 & Business Claims & Refers to the efficiency in any business claim. & $20 \%$ \\
\hline \multirow[t]{3}{*}{ Others } & 1 & $\begin{array}{l}\text { Strategic } \\
\text { Compatibility }\end{array}$ & Refers to the strategy matching degree and the recognition of values. & $40 \%$ \\
\hline & 2 & Company Reputation & Refers to the reputation of the container carriers. & $30 \%$ \\
\hline & 3 & Financial Situation & Refers to the financial situation of the container carriers. & $30 \%$ \\
\hline
\end{tabular}




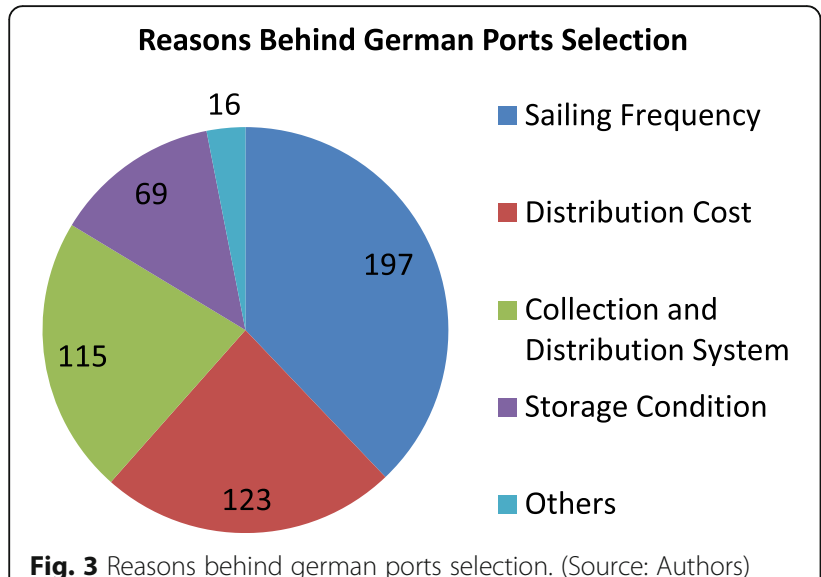

Fig. 3 Reasons behind german ports selection. (Source: Authors)

Delivery and Transit," 107 (20\%) selected "Additional Detention and Demurrage," 90 (16\%) selected "Extra Free Storage Condition," and seven (1\%) selected "others".

It seems that container carriers depend heavily on low-cost calling ports to achieve cost savings but have been forced to offer discounted freight rates and additional free detention, demurrage, and storage conditions, which does not create cost savings. Therefore, it is necessary to improve the traditional evaluation system based on the cost optimization of container liners and establish a new evaluation system of port selection based on customers.

\section{4. Methods}

Our scheme evaluation was based on indicator weights set by responses to our questionnaire survey. These weights were determined to be the most relevant factors, thus allowing internal linkages to be studied. Discussion and communication facilitated by the surveys was useful for understanding the concrete decision-making process. Likewise, the responses elucidated customers' concerns in port selection. Acquisition of this first-hand information is conducive to understanding selection and evaluation criteria based on customers' thinking. For these reasons, this method was chosen.

Additionally, there are hierarchical relationships among the various indicators in the questionnaire survey. The level indicators involved in customers' decision-making processes are composed of various subdivided indicators. These secondary indicators are the core elements of customers' evaluation and selection. The AHP method is effective in analyzing hierarchical and internal relationships between different indicators. Thus, it was selected as our evaluation procedure. The results were compared with and analyzed according to the questionnaire survey.

The level indicators and secondary indicators both originate from customers' questionnaire results regarding the aforementioned methods. The difference lies in that the weights of level indicators were set directly according to customers' voting proportion. Meanwhile, the weights of secondary indicators were derived from the expert survey results. However, both weights (level indicators and secondary indicators) are calculated using the AHP method. The evaluation system for port selection is shown in Fig. 4.

The raw data of the ports of Wilhelmshaven, Hamburg, Bremen, and Bremerhaven are presented in Table 2 below.

According to the questionnaire survey, 259 (41.5\%) participants selected "Freight Competitiveness," 223 (35.7\%) selected "Service Capability." Moreover, 122 (19.6\%) and 20 (3.2\%) participants selected "Cooperation and Relationship"

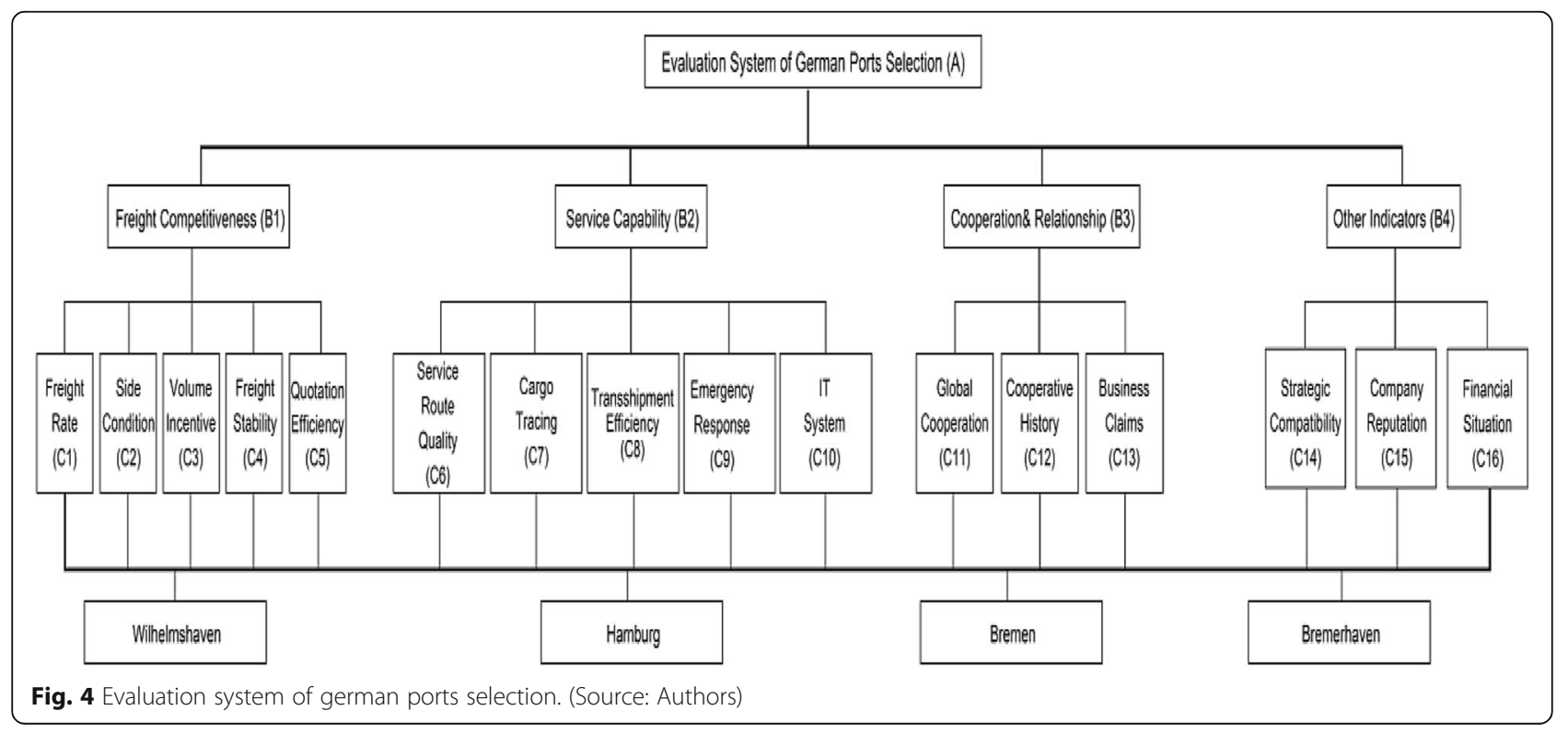


Table 2 Raw data of the indicators of four German ports (Source: Authors)

\begin{tabular}{|c|c|c|c|c|c|}
\hline Indicators & Wilhelmshaven & Hamburg & Bremen & Bremerhaven & Data Sources \\
\hline Freight Rate(C1) & $\$ 1400 /$ Feu & $\$ 1500 / F e u$ & $\$ 1500 /$ Feu & $\$ 1500 /$ Feu & Market Offer \\
\hline Side Condition(C2) & 14 Days & 7 Days & 9 Days & 9 Days & Market Offer \\
\hline Volume Incentive(C3) & $\$ 10 /$ Feu & $\$ 10 /$ Feu & $\$ 10 / \mathrm{Feu}$ & $\$ 10 /$ Feu & Expert Survey \\
\hline Freight Stability(C4) & 100 & 90 & 90 & 90 & Expert Survey \\
\hline Quotation Efficiency(C5) & 100 & 100 & 100 & 100 & Expert Survey \\
\hline Service Route Quality(C6) & 70 & 100 & 80 & 90 & Expert Survey \\
\hline Cargo Tracing(C7) & 100 & 100 & 100 & 100 & Expert Survey \\
\hline Transshipment Efficiency(C8) & 80 & 100 & 90 & 90 & Expert Survey \\
\hline Emergency Response(C9) & 90 & 95 & 90 & 95 & Expert Survey \\
\hline IT System(C10) & 100 & 100 & 100 & 100 & Expert Survey \\
\hline Global Cooperation(C11) & 100 & 100 & 100 & 100 & Expert Survey \\
\hline Cooperative History(C12) & 80 & 90 & 80 & 90 & Expert Survey \\
\hline Business Claims(C13) & 90 & 100 & 100 & 100 & Expert Survey \\
\hline Strategic Compatibility(C14) & 100 & 100 & 100 & 100 & Expert Survey \\
\hline Company Reputation(C15) & 100 & 100 & 100 & 100 & Expert Survey \\
\hline Financial Situation(C16) & 100 & 100 & 100 & 100 & Expert Survey \\
\hline
\end{tabular}

Note: Freight Rate and Side Condition are calculated by the container liners' offer, and other indicators are calculated from questionnaire surveys and interviews with customers and experts

and "Others," respectively. The choices made by the participants can be used as the weight of different indicators. Therefore, the weight of "Freight Competitiveness" is set as $41.5 \%$, the weight of "Service Capability" is set as $35.7 \%$, the weight of "Cooperation and Relationship" is set as $19.6 \%$, and that of "Others" is set to $3.2 \%$. The scheme evaluation based on the indicator weights set by the questionnaire survey is then compared with that under the AHP method.

\subsection{1 Scheme evaluation based on Indicator weights set} by questionnaire survey

As the raw data of the indicators were calculated using different dimensions and units, they need to be standardized for comparison. When the indicator is positive, its standardized formula is:

$$
x_{i j}^{\prime}=\frac{x_{i j}-x_{j}^{\min }}{x_{j}^{\max }-x_{j}^{\min }}
$$

When the indicator is negative, its standardized formula is:

$$
x_{i j}^{\prime}=\frac{x_{j}^{\max }-x_{i j}}{x_{j}^{\max }-x_{j}^{\min }}
$$

According to the above formulas, the processing of the raw data for Wilhelmshaven, Hamburg, Bremen, and Bremerhaven are presented in Table 3.

According to the questionnaire survey, the secondary indicators that constitute "Freight Competitiveness" are
"Freight Rate" (40\%), "Side Condition" (30\%), "Volume Incentive" (20\%), "Freight Stability" (5\%), and "Quotation Efficiency" (5\%), as set during the interviews and the fact that customers pay significant attention to the actual rate offer and related conditions, such as the credit terms, demurrage and detention terms, drop-off condition, and volume incentive when achieving the volume target of container carriers. Therefore, the weight of secondary indicators can be calculated as 16.6\% for "Freight Rate," $12.45 \%$ for "Side Condition," 8.3\% for "Volume Incentive," and $2.075 \%$ for both "Freight Stability" and "Quotation Efficiency."

Secondary indicators that constitute "Service Capability" are "Service Route Quality" (50\%), "Cargo Tracing” (20\%), "Transshipment Efficiency" (20\%), and 5\% for both "Emergency Response" and "IT System." This is based on the interviews and the fact that customers choose different services provided by container liners mainly through the evaluation of transit time, frequency, on-time performance, and uniqueness of the service route. Cargo tracing, transshipment efficiency, emergency response in urgent cases, and the possibility and convenience of IT system connection and data exchange are also major considerations. Therefore, the weight of secondary indicators can be calculated as $17.85 \%$ for "Service Route Quality," 7.14\% for both "Cargo Tracing" and "Transshipment Efficiency," and $1.785 \%$ for both "Emergency Response" and "IT System."

Secondary indicators that constitute "Cooperation and Relationship" are "Global Cooperation" (40\%), "Cooperative History" (40\%), and "Business Claims" (20\%). This is based on the interviews and the fact that customers pay almost 
Table 3 Standardization of evaluation indicators data in German ports. (Source: Authors)

\begin{tabular}{|c|c|c|c|c|}
\hline & Wilhelmshaven & Hamburg & Bremen & Bremerhaven \\
\hline Freight Rate(C1) & 0.07 & 0 & 0 & 0 \\
\hline Side Condition(C2) & 1 & 0.50 & 0.64 & 0.64 \\
\hline Volume Incentive(C3) & 1 & 1 & 1 & 1 \\
\hline Freight Stability(C4) & 1 & 0.90 & 0.90 & 0.90 \\
\hline Quotation Efficiency(C5) & 1 & 1 & 1 & 1 \\
\hline Service Route Quality(C6) & 0.70 & 1 & 0.80 & 0.90 \\
\hline Cargo Tracing(C7) & 1 & 1 & 1 & 1 \\
\hline Transshipment Efficiency(C8) & 0.80 & 1 & 0.9 & 0.90 \\
\hline Emergency Response(C9) & 0.95 & 1 & 0.95 & 1 \\
\hline IT System(C10) & 1 & 1 & 1 & 1 \\
\hline Global Cooperation(C11) & 1 & 1 & 1 & 1 \\
\hline Cooperative History(C12) & 0.89 & 1 & 0.89 & 1 \\
\hline Business Claims(C13) & 0.90 & 1 & 1 & 1 \\
\hline Strategic Compatibility(C14) & 1 & 1 & 1 & 1 \\
\hline Company Reputation(C15) & 1 & 1 & 1 & 1 \\
\hline Financial Situation(C16) & 1 & 1 & 1 & 1 \\
\hline
\end{tabular}

equal attention to global cooperation rather than being restricted to specific routes and the assessment of historical cooperation and future expectations. The efficiency of business claims also has an impact on customer choice. Therefore, the weight of secondary indicators can be calculated as $7.87 \%$ for both "Global Cooperation" and" Cooperative History," and 3.92\% for "Business Claims."

Other indicators include "Strategic Compatibility" (40\%) and "Company Reputation" and "Financial Situation" (both 30\%). This is also based on the interviews and the fact that customers pay much more attention to strategic consistency, value recognition, and the evaluation of the container liners' reputation and financial situation. Therefore, the weight of secondary indicators can be calculated as $1.28 \%$ for "Strategic Compatibility" and $0.96 \%$ for both "Company Reputation" and "Financial Situation."

According to the standardized data in Table 3 and the calculation formula

$$
Z_{i}=\sum_{j=1}^{p} \omega_{j} x_{i j}^{\prime}
$$

The final scores of the four alternative calling ports are presented in Table 4.

Based on the aforementioned evaluations, the order of preference for the German ports is as follows: Hamburg, Wilhelmshaven, Bremerhaven, and Bremen (Fig. 5, presents the order of preference).

\subsection{2 Scheme evaluation by AHP method}

The AHP is a decision analysis method proposed by American operations researcher T.L. Satty in the 1970s. It combines qualitative and quantitative analysis to solve complex multi-objective problems, and is widely applied in the scheme evaluation of port selection. Taih-Cherng et al. (2003) conducted a field survey of container carriers to analyze transshipment port selection from their perspective. Subsequently, Button et al. (2015) applied the AHP method to reveal the liners' seaport choice assessments. The advantages of AHP lie in its capacity to deal with a wide range of qualitative and quantitative variables. Its disadvantages originate from untrustworthy responses, or divergent and contrary answers (Nazemzadeh and Vanelsander, 2015). There have been many other applications of AHP to transport problems, proving it to be a valid approach to the current analysis. Therefore, the AHP method was chosen to evaluate port selection criteria in this paper. The calculation steps are as follows:

(1) Identify goals and indicators.

Evaluation indicators number $\mathrm{P}, u=\left\{u_{1}, u_{2}, \cdots \cdots, u_{p}\right\}$.

(2) Construction of judgment matrix.

Table 4 Final score of German ports based on customers investigation weight. (Source: Authors)

\begin{tabular}{ll}
\hline German Ports & Final Score \\
\hline Wilhelmshaven & 0.76 \\
Hamburg & 0.77 \\
Bremen & 0.73 \\
Bremerhaven & 0.76 \\
\hline
\end{tabular}


Final Score of German Ports Based on Customers Investigation

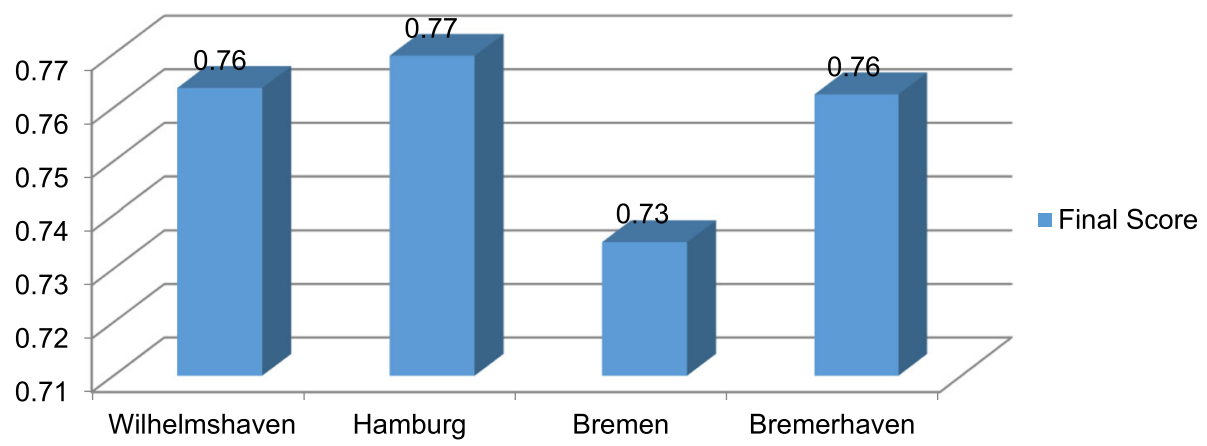

Fig. 5 Final score of german ports based on customers investigation. (Source: Authors)

Judging the value of the elements of the matrix reflects people's understanding of the relative importance of each element, generally using a scale from 1 to 9 and its reciprocal method. However, when the importance of the mutual comparison factor can be explained through a meaningful ratio, the value of the corresponding element of the judgment matrix is taken as the ratio. That is, the judgment matrix is obtained by $S=\left(u_{i j}\right)_{p \times p}$ Table 5 .

(3) Calculating the Judgment Matrix.

The maximum eigenvalue $\lambda_{\max }$ of the judgment matrix $S$ and its corresponding eigenvector $A$ are calculated using MATLAB software. This eigenvector is the order of importance of each evaluation factor, that is, the distribution of weight coefficients.

(4) Consistency Test.

To perform the consistency test of the judgment matrix, it is necessary to calculate the consistency indicator.

$$
C I=\frac{\lambda_{\max }-n}{n-1}
$$

The average random consistency indicator RI randomly constructs 500 sample matrices. The constructor randomly fills the upper triangles of the sample matrix with scales and their reciprocals. The values of the main diagonal are always 1 , and the reciprocal of the random number corresponding to the above position is used for the corresponding transposed position. Then, the consistency indicator values are calculated for each random sample matrix, and the average random consistency indicator value is obtained by averaging these values. When the random consistency ratio is, the results of the hierarchical analysis ranking are considered to be satisfactory, that is, the distribution of the weight coefficients is reasonable; otherwise, the value of the elements of the judgment matrix is adjusted, and the value of the weight coefficient is reallocated.

Table 6 presents the results of consistency indicator $R I$.

\section{(5) Judgment Matrix Construction and Solution of Weights.}

According to the indicator system, through the aforementioned scale method and the expert consultation method, eight experts in the field were selected and the degree of importance of the indicators was scored separately. The results were then further discussed and summarized internally, and the following $2 \times 2$ judgment matrix was obtained Table 7.

Table 5 Scale of relative importance of elements. (Source: Authors)

\begin{tabular}{ll}
\hline Scale & Meaning \\
\hline 1 & Two elements are equally important \\
5 & Compared with the two elements, the former is slightly more important than the latter. \\
7 & Compared with the two elements, the former is more important than the latter. \\
9 & Compared with the two elements, the former is obviously more important than the latter. \\
$2,4,6,8$ & Compared with the two elements, the former is absolutely more important than the latter. \\
Reciprocal & Intermediate value of the above adjacent judgment \\
\hline
\end{tabular}


Table 6 Average random consistency indicator. (Source: Authors)

\begin{tabular}{|c|c|c|c|c|c|c|c|c|c|c|c|c|c|c|}
\hline 1 & 2 & 3 & 4 & 5 & 6 & 7 & 8 & 9 & 10 & 11 & 12 & 13 & 14 & 15 \\
\hline 0 & 0 & 0.58 & 0.90 & 1.12 & 1.24 & 1.32 & 1.41 & 1.45 & 1.49 & 1.51 & 1.54 & 1.56 & 1.58 & 1.59 \\
\hline
\end{tabular}

The maximum eigenvalue of the judgment matrix is calculated using MATLAB software. To check the consistency of the judgment matrix, the consistency indicator needs to be calculated:

$$
C I=\frac{\lambda_{\max }-n}{n-1}=\frac{4.0047-4}{4-1}=0.0016
$$

The average random consistency indicator $R I=0.9$. The random consistency ratio is

$$
C R=\frac{C I}{R I}=\frac{0.0016}{0.9}=0.0017<0.10
$$

Therefore, the results of the hierarchical analysis ranking are considered to have satisfactory consistency, that is, the distribution of the weight coefficients is reasonable Table 8.

We use the analytic hierarchy method to find the index weight for each of the secondary indicators under the level indicators "Freight Competitiveness (B1)," "Service Capability (B2)," "Cooperation and Relationship (B3)," and "Other Indicators (B4)."

Under the level indicator "Freight Competitiveness (B1)," a judgment matrix $S=\left(u_{i j}\right)_{p \times p}$ is constructed for each sub-indicator. The results are shown in Table 9.

The maximum eigenvalue $\lambda_{\max }=5.0133$ of judgment matrix $S$ is calculated using MATLAB software. To check the consistency of the judgment matrix, the consistency index needs to be calculated:

$$
C I=\frac{\lambda_{\max }-n}{n-1}=\frac{5.0133-5}{5-1}=0.0033
$$

The average random consistency index is $R I=1.12$. The random consistency ratio is

$$
C R=\frac{C I}{R I}=\frac{0.0033}{1.12}=0.0030<0.10
$$

The results of the hierarchical analysis ranking are considered to have satisfactory consistency, that is, the distribution of the weight coefficients is very reasonable. The weights of the sub-indicators "Freight Rate (C1)," "Side Condition (C2)," "Volume Incentive (C3)," "Freight Stability (C4)," and "Quotation Efficiency (C5)" under the level indicator "Freight Competitiveness (B1)" are shown in Table 10.

Under the level indicator "Service Capability," a judgment matrix $S=\left(u_{i j}\right)_{p \times p}$ is constructed for each subindicator, as shown in Table 11.

The maximum eigenvalue $\lambda_{\max }=5.0022$ of judgment matrix $S$ is calculated using MATLAB software. To check the consistency of the judgment matrix, the consistency indicator needs to be calculated:

$$
C I=\frac{\lambda_{\max }-n}{n-1}=\frac{5.0022-5}{5-1}=5.5506 \mathrm{e}-04
$$

The average random consistency indicator is $R I=1.12$. The random consistency ratio is $C R=\frac{C I}{R I}=\frac{5.5506 \mathrm{e}-04}{1.12}=4$ $.9559 \mathrm{e}-04<0.10$.

Therefore, the results of the hierarchical analysis ranking are considered to have satisfactory consistency, that is, the distribution of the weight coefficients is very reasonable. The weights of the secondary indicators "Service Route Quality (C6),"'Cargo Tracing (C7)," "Transshipment Efficiency (C8)," "Emergency Response (C9)," and "IT System (C10)" under the first-level indicator "Service Capability (B2)" are shown in Table 12.

Under the level indicator "Cooperation and Relationship," judgment matrix $S=\left(u_{i j}\right)_{p \times p}$ is constructed for each sub-indicator. The results are shown in Table 13.

The maximum eigenvalue $\lambda_{\max }=3.0000$ of the judgment matrix $S$ is calculated using MATLAB software. To check the consistency of the judgment matrix, the consistency indicator needs to be calculated:

$$
C I=\frac{\lambda_{\max }-n}{n-1}=\frac{3.0000-3}{3-1}=0 \text { The average random }
$$
consistency indicator is $R I=0.58$. The random consistency ratio is

Table 8 Weight of level indicators. (Source: Authors)

\begin{tabular}{ll}
\hline Indicator level & Weight \\
\hline B1 & 0.39 \\
B2 & 0.37 \\
B3 & 0.20 \\
B4 & 0.04 \\
\hline
\end{tabular}

Table 7 The judgement matrix of the first-level indicators. (Source: Authors)

\begin{tabular}{lllll}
\hline & B1 & B2 & B3 & B4 \\
\hline B1 & 1 & 1 & 2 & 9 \\
B2 & 1 & 1 & 2 & 8 \\
B3 & $1 / 2$ & $1 / 2$ & 1 & 5 \\
B4 & $1 / 9$ & $1 / 8$ & $1 / 5$ & 1 \\
\hline
\end{tabular}


Table 9 The judgment matrix under "Freight Competitiveness". (Source: Authors)

\begin{tabular}{llllll}
\hline & $\mathrm{C} 1$ & $\mathrm{C} 2$ & $\mathrm{C} 3$ & $\mathrm{C} 4$ & $\mathrm{C5}$ \\
\hline $\mathrm{C} 1$ & 1 & 1 & 2 & 8 & 8 \\
$\mathrm{C} 2$ & 1 & 1 & 2 & 6 & 6 \\
$\mathrm{C} 3$ & $1 / 2$ & $1 / 2$ & 1 & 4 & 4 \\
$\mathrm{C} 4$ & $1 / 8$ & $1 / 6$ & $1 / 4$ & 1 & 1 \\
$\mathrm{C} 5$ & $1 / 8$ & $1 / 6$ & $1 / 4$ & 1 & 1 \\
\hline
\end{tabular}

$$
C R=\frac{C I}{R I}=\frac{0}{0.58}=0<0.10
$$

The results of the hierarchical analysis ranking are considered to have satisfactory consistency, that is, the distribution of the weight coefficients is very reasonable. The weights of the sub-indicators "Global Cooperation (C11),"“Cooperative History (C12)," and "Business Claims (C13)" under the first-level indicator "Cooperation and Relationship (B3)" are shown in Table 14.

Under the first-level indicator "Other Indicators(B4)," judgment matrix $S=\left(u_{i j}\right)_{p \times p}$ is constructed for each subindicator. The results are shown in Table 15.

The maximum eigenvalue $\lambda_{\max }=5.0133$ of judgment matrix $S$ is calculated using MATLAB software. To check the consistency of the judgment matrix, the consistency indicator needs to be calculated:

$$
C I=\frac{\lambda_{\max }-n}{n-1}=\frac{3.0000-3}{3-1}=0
$$

The average random consistency indicator is $R I=1.12$. The random consistency ratio is

$$
C R=\frac{C I}{R I}=\frac{0}{0.58}=0<0.10
$$

Therefore, the results of the hierarchical analysis ranking are considered to have satisfactory consistency, that is, the distribution of the weight coefficients is very reasonable. The weights of the sub-indicators "Strategic Compatibility(C14)"," Company Reputation(C15)"and "Financial Situation(C16)" under the first-level indicator "Others" are shown in Table 16.

Therefore, under the AHP, the weights and comprehensive weights of the level indicators and secondary

Table 10 Weight of secondary indicators under "Freight Competitiveness". (Source: Authors)

\begin{tabular}{ll}
\hline Secondary Indicator & Weight \\
\hline C1 & 0.38 \\
C2 & 0.34 \\
C3 & 0.19 \\
C4 & 0.05 \\
C5 & 0.05 \\
\hline
\end{tabular}

Table 11 The judgement matrix under "Service Capability". (Source: Authors)

\begin{tabular}{llllll}
\hline & C6 & C7 & C8 & C9 & C10 \\
\hline C6 & 1 & 2 & 2 & 9 & 9 \\
C7 & $1 / 2$ & 1 & 1 & 4 & 4 \\
C8 & $1 / 2$ & 1 & 1 & 4 & 4 \\
C9 & $1 / 9$ & $1 / 4$ & $1 / 4$ & 1 & 1 \\
C10 & $1 / 9$ & $1 / 4$ & $1 / 4$ & 1 & 1 \\
\hline
\end{tabular}

indicators of port selection by customers are calculated and shown as Table 17.

The dimensions and units of each indicator are different and cannot be directly compared and calculated, so they need to be standardized before evaluation.

When the indicator is positive, its standardized formula is:

$$
x_{i j}^{\prime}=\frac{x_{i j}-x_{j}^{\min }}{x_{j}^{\max }-x_{j}^{\min }}
$$

When the indicator is negative, its standardized formula is:

$$
x_{i j}^{\prime}=\frac{x_{j}^{\max }-x_{i j}}{x_{j}^{\max }-x_{j}^{\min }}
$$

According to the above formula, the raw data of the port of Wilhelmshaven, Hamburg, Bremen, and Bremerhaven are processed, and the standardized data forms are shown in Table 18.

According to the calculation formula $Z_{i}=\sum_{j=1}^{p} \omega_{j} x_{i j}^{\prime}$, the scores of the ports of Wilhelmshaven, Hamburg, Bremen, and Bremerhaven are calculated and shown as Table 19.

The aforementioned AHP evaluation system reveals the priority of four alternative calling ports in Germany: Hamburg, Wilhelmshaven, Bremerhaven, and Bremen.

\subsection{Results and discussion}

According to evaluation based on indicator weights (as set by questionnaire results), there was no difference in priority among the four alternative calling ports. The same results were found using the AHP evaluation

Table 12 Weight of secondary indicators under "Service Capability". (Source: Authors)

\begin{tabular}{ll}
\hline Secondary Indicator & Weights \\
\hline C6 & 0.46 \\
C7 & 0.22 \\
C8 & 0.22 \\
C9 & 0.05 \\
C10 & 0.05 \\
\hline
\end{tabular}


Table 13 The judgment matrix under "Cooperation and Relationship". (Source: Authors)

\begin{tabular}{llll}
\hline & $\mathrm{C} 11$ & $\mathrm{C} 12$ & $\mathrm{C} 13$ \\
\hline $\mathrm{C} 11$ & 1 & 1 & 2 \\
$\mathrm{C} 12$ & 1 & 1 & 2 \\
$\mathrm{C} 13$ & $1 / 2$ & $1 / 2$ & 1 \\
\hline
\end{tabular}

system. However, under this same customer- oriented thinking, slightly different concerns are evident.

The indicator of "freight competitiveness" has a significantly higher weight than other indicators, as evidenced in the survey results. This reflects customers' high attention of freight offer in the questionnaire survey. As dominant factors, freight rate, side condition, volume incentive, freight stability, and quotation efficiency attracted more attention in customers' port selection. Weights of "Freight Competitiveness" and "Service Capability" are roughly equal under the AHP evaluation system, showing similar levels of concern for freight offer and customer service. Through further analysis of the secondary indicators, it was found that the main differences come from "Cargo Tracing" and "Transshipment Efficiency." The implicit indicators affecting port selection may be overlooked by customers in the questionnaire survey, but were well considered under the AHP evaluation system. AHP results were both supplementary and confirmatory to the questionnaire conclusions.

Additionally, there is consistency in the main secondary indicators under both evaluation systems. Service route quality, freight rate, and side condition are the key subdividing indicators of customers' port selection. These effects can also be verified in practice, as customers focus on transit time, frequency, on-time performance, and uniqueness in making port selections. Such choices were made while also considering the freight offer and its side conditions.

\section{Conclusions}

The difference between customer-oriented thinking and product-oriented thinking in port selection rests upon differing priorities in the decision-making process. Under customer-oriented thinking, key aspects were focused on customers' wishes. Analysis of port selection

Table 14 Weight of secondary indicator under "Cooperation and Relationship". (Source: Authors)

\begin{tabular}{ll}
\hline Secondary Indicator & Weights \\
\hline C11 & 0.40 \\
C12 & 0.40 \\
C13 & 0.20 \\
\hline
\end{tabular}

Table 15 The judgment matrix under "Others". (Source: Authors)

\begin{tabular}{llll}
\hline & $\mathrm{C} 14$ & $\mathrm{C} 15$ & $\mathrm{C} 16$ \\
\hline $\mathrm{C} 14$ & 1 & 2 & 2 \\
$\mathrm{C} 15$ & $1 / 2$ & 1 & 1 \\
$\mathrm{C} 16$ & $1 / 2$ & 1 & 1 \\
\hline
\end{tabular}

indicators in customers' decision-making processes revealed that highly desired ports accorded with customers' requirements. Therefore, the rationality of decision-making can be improved. In this research, scheme evaluation was based on indicator weights set by questionnaire responses, as well as the AHP method. "Freight Competitiveness" and "Service Capability" of container carriers were found to be key indicators. Emphasis can be placed on "Service route quality," "Freight rate" and "Side condition" as key secondary indicators.

Product-oriented thinking has been very common in the industry; however, changes are necessary. Given the trend of upsizing large-scale container vessels, the relationship between supply and demand has reversed, and the situation of excess capacity, or partial excess, will continue in the future. The traditional evaluation system depends on customers' acceptance. Notably, due to differing priorities between customers and container carriers, port selection is sometimes inconsistent.

Perspectives differ between customer-oriented and product-oriented evaluation systems. Yet, this does not mean that the two methods should be completely separated. On the contrary, a comparative analysis should be implemented using both evaluation systems. Doing so could greatly improve the rationality of port selection.

\section{Contribution}

This paper proposes a new research idea regarding port selection, that is, replacing "product-oriented" thinking with "customer-oriented" thinking. It also examines the relevant indicator system and the underlying logic, beyond that of customer port selection, changing the possible deviation caused by traditional optimization.

Based on the questionnaire survey and interviews with active customers of container carriers, the paper covers

Table 16 Weights of secondary indicators under "Others". (Source: Authors)

\begin{tabular}{ll}
\hline Secondary Indicator & Weights \\
\hline C14 & 0.50 \\
C15 & 0.25 \\
C16 & 0.25 \\
\hline
\end{tabular}


Table 17 Weights of level indicators and secondary indicators by AHP. (Source: Authors)

\begin{tabular}{lllll}
\hline $\begin{array}{l}\text { Level } \\
\text { Indicators }\end{array}$ & Weights & $\begin{array}{l}\text { Secondary } \\
\text { Indicators }\end{array}$ & Weights & $\begin{array}{l}\text { Comprehensive } \\
\text { weight }\end{array}$ \\
\hline B1 & 0.385 & C1 & 0.38 & 0.14 \\
& & C2 & 0.34 & 0.13 \\
& & C3 & 0.19 & 0.07 \\
& & C4 & 0.05 & 0.02 \\
B2 & C5 & 0.05 & 0.02 \\
& 0.3742 & C6 & 0.46 & 0.17 \\
& & C7 & 0.22 & 0.08 \\
& & C8 & 0.21 & 0.08 \\
& & C9 & 0.05 & 0.02 \\
B3 & C10 & 0.05 & 0.02 \\
& 0.1978 & C11 & 0.40 & 0.08 \\
& & C12 & 0.40 & 0.08 \\
B4 & & C13 & 0.20 & 0.04 \\
& & C14 & 0.50 & 0.02 \\
& & C15 & 0.25 & 0.01 \\
& & C16 & 0.25 & 0.01 \\
\hline
\end{tabular}

Table 18 Standardized data for ports of Wilhelmshaven, Hamburg, Bremen, and Bremerhaven. (Source: Authors)

\begin{tabular}{|c|c|c|c|c|}
\hline & Wilhelmshaven & Hamburg & Bremen & Bremerhaven \\
\hline Freight Rate(C1) & 0.07 & 0 & 0 & 0 \\
\hline Side Condition(C2) & 1 & 0.50 & 0.64 & 0.64 \\
\hline $\begin{array}{l}\text { Volume } \\
\text { Incentive(C3) }\end{array}$ & 1 & 1 & 1 & 1 \\
\hline Freight Stability(C4) & 1 & 0.90 & 0.90 & 0.90 \\
\hline $\begin{array}{l}\text { Quotation } \\
\text { Efficiency(C5) }\end{array}$ & 1 & 1 & 1 & 1 \\
\hline $\begin{array}{l}\text { Service Route } \\
\text { Quality(C6) }\end{array}$ & 0.70 & 1 & 0.80 & 0.90 \\
\hline Cargo Tracing(C7) & 1 & 1 & 1 & 1 \\
\hline $\begin{array}{l}\text { Transshipment } \\
\text { Efficiency(C8) }\end{array}$ & 0.80 & 1 & 0.90 & 0.90 \\
\hline $\begin{array}{l}\text { Emergency } \\
\text { Response(C9) }\end{array}$ & 0.95 & 1 & 0.95 & 1 \\
\hline IT System(C10) & 1 & 1 & 1 & 1 \\
\hline $\begin{array}{l}\text { Global } \\
\text { Cooperation(C11) }\end{array}$ & 1 & 1 & 1 & 1 \\
\hline $\begin{array}{l}\text { Cooperative History } \\
\text { (C12) }\end{array}$ & 0.89 & 1 & 0.89 & 1 \\
\hline $\begin{array}{l}\text { Business } \\
\text { Claims(C13) }\end{array}$ & 0.90 & 1 & 1 & 1 \\
\hline $\begin{array}{l}\text { Strategic } \\
\text { Compatibility(C14) }\end{array}$ & 1 & 1 & 1 & 1 \\
\hline $\begin{array}{l}\text { Company } \\
\text { Reputation(C15) }\end{array}$ & 1 & 1 & 1 & 1 \\
\hline $\begin{array}{l}\text { Financial } \\
\text { Situation(C16) }\end{array}$ & 1 & 1 & 1 & 1 \\
\hline
\end{tabular}

Table 19 Final score for ports of Wilhelmshaven, Hamburg, Bremen, and Bremerhaven under AHP. (Source: Authors)

\begin{tabular}{ll}
\hline & Comprehensive scores \\
\hline Wilhelmshaven & 0.78 \\
Hamburg & 0.79 \\
Bremen & 0.75 \\
Bremerhaven & 0.78 \\
\hline
\end{tabular}

the main customer categories, including large-scale cargo owners, small- and medium-sized cargo owners, a global NVOCC, small- and medium-sized freight-forwarding companies, and so on, providing a new way of thinking and direction for further research on port selection so as to better meet customers' service requirements.

\section{Acknowledgements}

I would like to thank the reviewers for their constructive comments and editorial suggestions.

\section{Corresponding author details}

Yisong Lin, PhD of Shanghai Maritime University, over 16 years of working experience in COSCO group including over 10 years of management experience in Asia-Pacific Trade Division, Transpacific Division, Europe Trade Division. Research covers service route design and management, yield management, vendor management, pricing and allocation management etc. Three Main Publications:

(1) Yisong Lin(2019) The Practice of Container Liner Transportation and Management. China: China Customs Press.

(2) Yisong Lin(2008) The Practice of International Container Liner transportation. China: China Customs Press.

(3) Yisong Lin(2013) The Baltic Feeder line Layout Planning and Decision Making Research of C Company. Shanghai Jiaotong University, Shanghai, China

\section{Authors' contributions}

XF Wang analyzed and interpreted the data. YS Lin conceived and designed the analytic framework, and was a major contributor in writing the manuscript. All authors read and approved the final manuscript.

\section{Funding}

Funding information is not applicable.

\section{Availability of data and materials}

The datasets used during the current study are available from the corresponding author on reasonable request.

\section{Competing interests}

The authors declare that they have no competing interests.

Received: 1 April 2019 Accepted: 28 October 2019

Published online: 10 December 2019

\section{References}

1. Taih-Cherng, L., Helen, T., \& Anthony, B. (2003). Transhipment port selection and decision-making behavior: Analysing the Taiwanese case. International Journal of Logistics Research and Applications, 6, 229-244. https://doi.org/10. 1080/13675560310001626990.

2. Guy, E., \& Urli, B. (2006). Port selection and multicriteria analysis: An application to the Montreal-New York alternative. Marit Econ Logistics, 8, 169-186. https://doi.org/10.1057/palgrave.mel.9100152.

3. Chang, Y. T., Lee, S. Y., \& Tongzon, J. L. (2008). Port selection factors by shipping lines: Different perspectives between trunk liners and feeder service providers. Marine Policy, 32, 877-885. https://doi.org/10.1016/j. marpol.2008.01.003.

4. Nguyen, K. T. (2011). Studying port selection on liner routes: An approach from logistics perspective. Research in Transportation Economics, 32, 39-53. 
5. Kadaifci, C ,Asan, U ,Serdarasan, S, Arican, U . (2019). A new rule-based integrated decision making approach to container transshipment terminal selection. Maritime Policy \& Management,(46)2:237-256.DOl: https://doi.org/ 10.1080/03088839.2018.1489149.

6. Nazemzadeh, M., \& Vanelslander, T. (2015). The container transport system: Selection criteria and business attractiveness for north-European ports. Maritime Economics \& Logistics, 17, 221. https://doi.org/10.1057/mel.2015.1.

7. Bart, W. W., Anthony Van Der, H., \& Theo, E. N. (2008). Port and terminal selection by deep-sea container operators. Maritime Policy \& Management, 35, 517-534. https://doi.org/10.1080/03088830802469329.

8. Tand, L. C., Low, J. M. W., \& Lam, S. W. (2011). Understanding port choice behavior-a network perspective. Networks Spatial Economics, 11, 65-82. https://doi.org/10.1007/s11067-008-9081-8.

9. Veldman, S, Garcia-Alonso, L, Vallejo-Pinto, JA. (2013). A port choice model with logit models: A case study for the Spanish container trade. International Journal of Shipping and Transport Logistics,(5):373-389.DOI: https://doi.org/10.1504/IJSTL.2013.055277.

10. Onut, S., Tuzkaya, U. R., \& Tourn, E. (2011). Selecting container port via a fuzzy ANP-based approach: A case study in the Marmara region, Turkey. Transport Policy, 18, 181-193. https://doi.org/10.1016/j.tranpol.2010.08.001.

11. Chou, C. C. (2010). AHP model for the container port choice in the multipleports region. Journal of Marine Science and Technology, 18, 221-232.

12. Button, K., Chin, A., \& Kramberger, T. (2015). Incorporating subjective elements into liners' seaport choice assessments. Transport Policy, 44, 125 133. https://doi.org/10.1016/j.tranpol.2015.07.006

13. Yeo, G. T., Ng, A. K. Y., Lee, P. T. W., \& Yang, Z. L. (2014). Modelling port choice in an uncertain environment. Maritime Policy \& Management, 41, 251-267. https://doi.org/10.1080/03088839.2013.839515.

14. Notteboom, T. E., Parola, F., Satta, G., \& Pallis, A. A. (2017). The relationship between port choice and terminal involvement of alliance members in container shipping. Journal of Transport Geography, 64, 158-173. https://doi. org/10.1016/j.jtrangeo.2017.09.002.

15. Tongzon, JL. (2009). Port choice and freight forwarders. Transportation Research Part E-Logistics and Transportation Review,(45):186-195.DOl: https://doi.org/10.1016/j.tre.2008.02.004

16. Kashiha, M, Thill, JC, Depken, C A. (2016). Shipping route choice across geographies: Coastal vs. landlocked countries. Transportation Research Part E,(91):1-14.DOl: https://doi.org/10.1016/j.tre.2016.03.012

17. Balci, G., Cetin, I. B., \& Esmer, S. (2018). An evaluation of competition and selection criteria between dry bulk terminals in Izmir. Journal of Transport Geography, 69, 294-304. https://doi.org/10.1016/j.jtrangeo.2018.05.011.

\section{Publisher's Note}

Springer Nature remains neutral with regard to jurisdictional claims in published maps and institutional affiliations.

\section{Submit your manuscript to a SpringerOpen ${ }^{\circ}$ journal and benefit from:}

- Convenient online submission

- Rigorous peer review

- Open access: articles freely available online

- High visibility within the field

- Retaining the copyright to your article

Submit your next manuscript at $\boldsymbol{\nabla}$ springeropen.com 